\title{
Rancang Bangun Pemetaan UMKM Kota Tegal Berbasis Sistem Informasi Geografis
}

\author{
Cica Noviyanti ${ }^{1}$, Wati Erawati ${ }^{2}$, Hendra Lesmana ${ }^{3}$ \\ 1Prodi Sistem Informasi, Universitas Bina Sarana Informatika \\ 2,3Prodi Sistem Informasi Akunatnsi, Universitas Bina Sarana Informatika \\ ${ }^{1}$ cica.cvi@bsi.ac.id, ${ }^{2}$ wati.wti@bsi.ac.id, 3hendra.hla@bsi.ac.id
}

\begin{abstract}
Rapid technological development, the website has become a mandatory media for every agency, company and organization, especially in conveying information to the wider community. MSMEs have an important role in the success of national economic development and are also able to absorb a lower middle class workforce. Likewise, MSMEs in Tegal City, have now become pillars of the economic growth of the people of Tegal City. The City of Tegal MSMEs presents data on the profile of MSMEs that are still conventional and difficult to find, both in location and profile. Geographical Information Systems (GIS) should have been implemented at this time, by utilizing GIS, investors, customers and the wider community will easily get the MSME information. MSME MSMEs Tegal City was designed using the Waterfall method with a Website platform using the PHP programming language and Mysql database. The hope is that this Tegal City SME GIS can become a media of information, promotion to achieve competitiveness in this globalization era.
\end{abstract}

Keywords: Geografis Information System, MSMEs, Waterfall

Abstrak: Perkembangan teknologi kian pesat, website sudah menjadi media wajib bagi setiap instansi, perusahaan dan organisasi khususnya dalam menyampaikan informasi kepada masyarakat luas. UMKM mempunyai peranan enting dalam mensukseskan pembangunan ekonomi nasional dan juga mampu menyerap tenaga kerja kelas menengah ke bawah. Begitu pula UMKM di Kota Tegal, kini sudah menjadi pilar pertumbuhan perekonomian masyarakat Kota Tegal. UMKM Kota Tegal penyajian data profil UMKM masih konvensional dan sulit dicari baik lokasi maupun profilnya. Sistem Informasi Geografis (SIG) seharusnya sudah diterapkan saat ini, dengan memanfaatkan SIG maka investor, customer dan masyarakat luas akan mudah mendapatkan informasi UMKM tersebut.. SIG UMKM Kota Tegal dirancang menggunakan metode Waterfall dengan platform Website menggunahakan bahasa pemrogramman PHP dan database Mysql. Harapanya agar SIG UMKM Kota Tegal ini dapat menjadi media informasi, promosi untuk memcapai daya saing di era globalisasi ini.

Kata kunci: Sistem Informasi Geografis, UMKM, Waterfall

(7) 8 This is an open access article distributed under the Creative Commons Attribution License, which permits unrestricted use, distribution, and reproduction in any medium, provided the original work is properly cited. (02019 by author and IJSE-Indonesian Journal on Software Engineering.

\section{A. PENDAHULUAN}

Perkembangan teknologi dan Informasi saat ini, sudah merubah paradigma proses bisnis diseluruh lapisan baik instansi pemerintah, perusahaan besar maupun kecil, pendidikan dan organisasi.

Undang-Undang Republik Indonesia No 20 tahun 2008 tentang Usaha Mikro, Kecil dan Menengah mengatakan bahwa UMKM bertujuan untuk menumbuhkan dan mengembangkan usahanya dalam rangka membangun perekonomian nasional berdasarkan demokrasi ekonomi yang berkeadilan berbasis potensi daerah, berorientasi pasar, meningkatkan daya saing usaha. UMKM juga berperan dalam mensukseskan pembangunan daerah, menciptakan lapangan kerja, pemerataan pendapatan, pertumbuhan ekonomi dan pengentasan rakyat dari kemiskinan (UU no 20, 2002). Dengan berbasis potensi daerah maka UMKM ada disetiap daerah diseluruh Indonesia. 
Dari hasil wawancara dengan Bapak Agus Jaya,SE selaku Kepala Seksi Pemberdayaan UMKM di Dinas Koperasi, UKM dan Perdagangan Kota Tegal mengatakan bahwa data UMKM mengandalkan dari Badan Pusat Statistik Kota Kota Tegal. Data yang disajikan dalam bentuk tabel, kurang detail, disajikan keseluruhan dari tiap-tiap kecamatan. Dari hasil penelusuran penulis, mencari data UMKM Kota Tegal di internet sangat sulit, belum menemukan data yang dikemas dengan baik untuk kemudahan masyarakat.

Sistem Informasi Geografis (SIG) mampu menyajikan informasi UMKM dalam bentuk peta atau map sehingga lebih menarik, tidak membosankan dari pada berbentuk tekstual [Minarni and Delfia, 2016]. Sistem Informasi Geografis akan menampilkan titik lokasi usaha serta, kegiatan usaha, data-data usaha seperti nama usaha, produk usaha, kegiatan usaha, jenis usaha, keterangan usaha, dan alamat usaha dalam bentuk visual [Abdullah, 2018]. Dengan adanya GIS masyarakat lebih mudah dalam melihat persebaran UMKM karena dilengkapi dengan tampilan grafis [Maita and Nurhikmah, 2018]. Sistem informasi berbasis cloud computing dapat menjadi solusi bagi para pelaku usaha khususnya UMKM untuk dapat berubah dari konvensional ke penerapan teknologi untuk dapat bersaing diera globalisasi [Warjiyono, 2017].

Perancangan Sistem Informasi Geografis Pemetaan sebaran UKM Kota Tegal diharapkan mampu membantu masyarakat untuk dengan mudah mendapatkan informasi, profil, produk UMKM dengan sajian dalam bentuk peta.

\section{B. TINJAUAN PUSTAKA}

\section{UMKM}

Menurut Undang-Undang Republik Indonesia No. 20 Tahun 2008 tentang Usaha Mikro, Kecil, Menengah bahwa:

a. Usaha Mikro merupakan usaha yang dimiliki perorangan atau badan usaha perorangan dengan kekayaan paling banyak Rp 50.000 .000 (lima puluh juta rupiah) tidak termasuk tanah dan bangunan atau memiliki profit tahunan paling banyak Rp 300.000 .000 (tiga ratus juta rupiah).

b. Usaha Kecil merupakan usaha milik perorangan atau badan usaha memiliki kekayaan bersih lebih dari Rp 50.000.000 (lima puluh juta rupiah) hingga maksimal Rp 500.000.000 (lima ratus juta rupiah) tidak termasuk tanah dan bangunan atau memiliki profit lebih dari Rp 300.000.000 (tiga ratus juta rupiah) hingga paling banyak Rp 2.500.000.000 (dua milyar lima ratus juta rupiah).

c. Usaha Menengah merupakan usaha milik perorangan atau badan usaha dengan jumlah kekayaan bersih lebih dari Rp500.000.000 (lima ratus juta rupiah) hingga paling banyak Rp 10.000.000.000 (sepuluh milyar rupiah) tidak termasuk tanah dan bangunan atau memiliki hasil penjualan tahunan lebih dari $\mathrm{Rp} 2.500 .000 .000$ (dua milyar lima ratus juta rupiah) hingga paling banyak Rp 50.000.000.000 (lima puluh milyar rupiah) [UU No. 20 Tahun 2008, 2008].

\section{Sistem Informasi Geografis}

Sistem Informasi Geografis (SIG) atau Geographic Information Systems (GIS) diperkenalkan pertama kali pada tahun 1960 dengan tujuan untuk menyelesaikan persoalan geografis atau permukaan bumi saja. Tetapi sesuai dengan perkembangan teknologi dan ilmu pengetahuan maka SIG digunakan untuk menyelesaikan persoalan diberbagai bidang seperti pariwisata,, sosial, pendidikan, kesehatan, pertanian dan bidang lainnya.

Sistem Informasi Geografis (SIG) dapat memberikan kemudahan melihat visual hamparan bumi dapat menyimpanan, memproses, dan menampilakannya berdasarkan citra satelit, foto udara, peta bahkan data statistik. SIG juga mampu mengakomodasi perubahan data, dengan pemutakhiran data yang lebih mudah [Rekatama, 2018]. Sistem Informasi geografis diperlukan untuk mempermudah mengetahui daerah secara visual sehingga mempercepat dalam mengambil keputusan [Sasongko, 2016]. Penerapan sistem informasi geografis akan mendapatkan kemudahan dalam mendapatkan atau mengakses informasi [Eldita et al., 2018]. 


\section{Metode Pengembangan Perangkat Lunak}

Metode pengembangan perangkat lunak yang digunakan adalah merode waterfall atau disebut air terjun. Model waterfall merupakan model sekuensial yang diawalai dari analisis, desain, pengodean, pengujian, dan tahap pendukung (support) [Rosa and Shalahuddin, 2016].

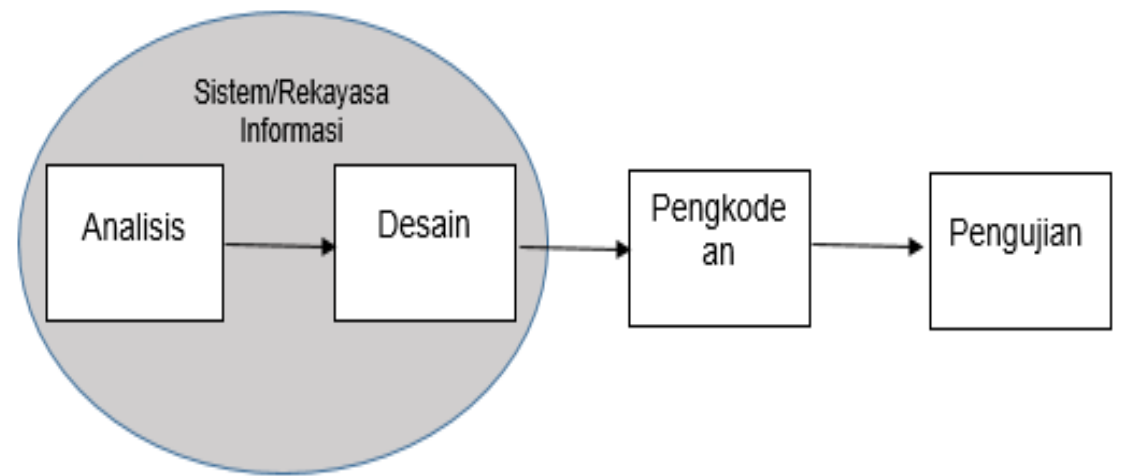

Sumber: [Rosa and Shalahuddin, 2016]

Gambar 1. Menjelaskan :

Gambar 1. Model Waterfall

1. Analisis Kebutuhan Perangkat Lunak

Melakukan Proses mengunpulkan kebutuhan sistem atau perangkat lunak untuk dapat dipahami mau seperti apa perangkat lunak yang dibutuhkan oleh pengguna. Saat menentukan spesifikasi kebutuhan perangkat diperlukan didokumentasi.

2. Desain

Melakukan perancangan seperti struktur data, arsitektur perangkat lunak, perancangan antar muka, Perancanagn tersebut akan diimplementasikan kedalam program di tahap berikutnya. Perancangan perangkat lunak yang dihasilkandiperlukan dokumentasik.

3. Pembuatan Kode Program

Dari perancangan diimplementasikan kedalam program dengan menggunakan bahasa pemrograman.

4. Pengujian

Pengujian dilakukan untuk menguji logika dan fungsional perangkat lunak. Sekaligus untuk memastikan semua logiak dan fungsi berjalan dengan baik, mengecek kesalahan serta memastikan output yang dihasilkan sesuai yang diinginkan

5. Pendukung (Support) atau pemeliharaan (Maintenance)

Support dilakukan jika ada perubahan pada perangkat lunak atau kesalahan yang terjadi setelah dioperasikan oleh pengguna. Pemeliharaan dilakukan jika ada pengembangan fitur dari perangkat luna karena perkembangan organisasi atau menyesuaikan kebutuhan baru pengguna sehinga tdk perlu untuk membuat perangkat lunak baru lagi.

\section{BackBox Testing}

Pengujian perangkat menggunakan black-box testing. Menurut Rosa dan Salahuddin dalam [Fridayantie and Mahdiati, 2016]. "Black-box testing adalah perangkat lunak dari segi spesifikasi fungsional tanpa menguji desain dan kode program". Pengujian dimaksudkan untuk mengetahui apakah fungsi-fungsi, masukan, dan keluaran dari perangkat lunak sesuai dengan spesifikasi yang dibutuhkan. Metode Black Box memfokuskan pada keperluan fungsional dari program. Adapun beberapa kategori kesalahan yang diuji oleh Black Box testing, diantaranya yaitu seperti Fungsi-fungsi yang salah atau hilang., kesalahan interface, Kesalahan dalam struktur data atau akses database eksternal, Kesalahan performa., Kesalahan inisialisasi dan terminasi.

\section{METODE PENELITIAN}

Metode penelitian yang digunakan, yaitu:

1. Metode pengembangan perangkat lunak 
Metode waterfall dari [Rosa and Shalahuddin, 2016], yaitu :

a. Analisis Kebutuhan Perangkat Lunak Menganalisa kebutuhan sistem yang dibutuhkan baik secara fungsional maupun non fungsional yang digunakan untuk mempermudah dalam proses pembuatan program..

b. Desain

Proses desain perancangan program seperti perancangan basis data dan perancangan antar muka, serta kebutuhan database yang digambarkan dalam bentuk Entity Relationship Diagram (ERD) dan Logical Record Structure (LRS) beserta struktur navigasinya.

c. Pengkodean

Proses pengkodean dalam pembuatan website menggunakan bahasa pemprograman seperti HTML, PHP, CSS dan Javascript dengan bantuan software Dreamweaver CC 2015 dengan XAMPP sebagai web server.

d. Pengujian

Pengujian dalam hal ini menggunakan Black Box Testing yang berfokus pada perangkat lunak dari segi fungsional, memastikan bahwa semua bagian sudah diuji. Hal ini dilakukan untuk meminimalisir kesalahan (Error) dan memastikan keluaran yang dihasilkan sesuai dengan yang diinginkan.

e. Pemeliharaan

Tahap Pemeliharaan dilakukan setelah program dioperasikan, Pemeliharaan terjadi karena adanya kesalahan yang muncul dan tidak terdeteksi saat pengujian atau program harus beradaptasi dengan lingkungan baru sehingga diperluakan untuk pemeliharaan sistem.

2. Teknik Pengumpulan Data

Teknik pengumpulan data yang dilakukan oleh penulis dalam mengumpulkan data untuk pembuatan Tugas Akhir ini adalah:

a. Observasi

Dalam metode ini penulis melakukan observasi secara langsung pada lokasi-lokasi UKM di Kota Tegal untuk membagikan kuesioner guna mendapatkan data-data UKM serta foto yang dibutuhkan untuk pembuatan Tugas Akhir ini.

b. Wawancara

Pengumpulan data yang digunakan dalam penelitian yakni dengan melakukan tanya jawab langsung kepada bapak Agus Jaya,SE selaku narasumber sebagai Kepala Seksi Pemberdayaan UMKM untuk mendapatkan data permasalahan yang ada pada Dinas Koperasi, UKM dan Perdagangan. 
c. Studi Pustaka

Tambahan data juga diperlukan dalam membuat Tugas Akhir ini, penulis mendapatkan data-data tersebut dari buku, jurnal, ebook, laporan Tugas Akhir, internet untuk membantu dalam penulisan laporan maupun untuk mendapatkan referensi-referensi dalam perancangan web yang dibuat.

\section{E. HASIL DAN PEMBAHASAN}

1. Analisis

Menentukan kebutuhan fungsional yaitu kebutuhan hak akses yaitu menentukan hak akses pengguna yaitu admin, visitir dan Kepala Dinas Koperasi, UKM, dan Perdagangan Kota Tegal, selanjutnya menentukan kebutuhan sistem yaitu sistem menyediakan form login, beranda, data admin, kategori, data UKM, peta sebaran UKM, Galeri dan Artikel. Selanjutnya menentukan kebutuhan non fungsional yaitu menentukan hardware dan software yang dibutuhkan dalam membuat sistem ini. Perangkat keras dibutuhkan seperangakt laptop dengan spesifikasi baik, sedangkan perangkat lunak yang dibutuhkan adalahbahasa pemrograman PHP, Web server : Apache, Editor web : Dreamweaver CS6, Sublime Text 3, Database : Mysql, Web browser : Mozilla Firefox, Google Chrome dan CorelDRAW X7

2. Desain

Membuat rancangan antar muka atau user interface dan rancangan database

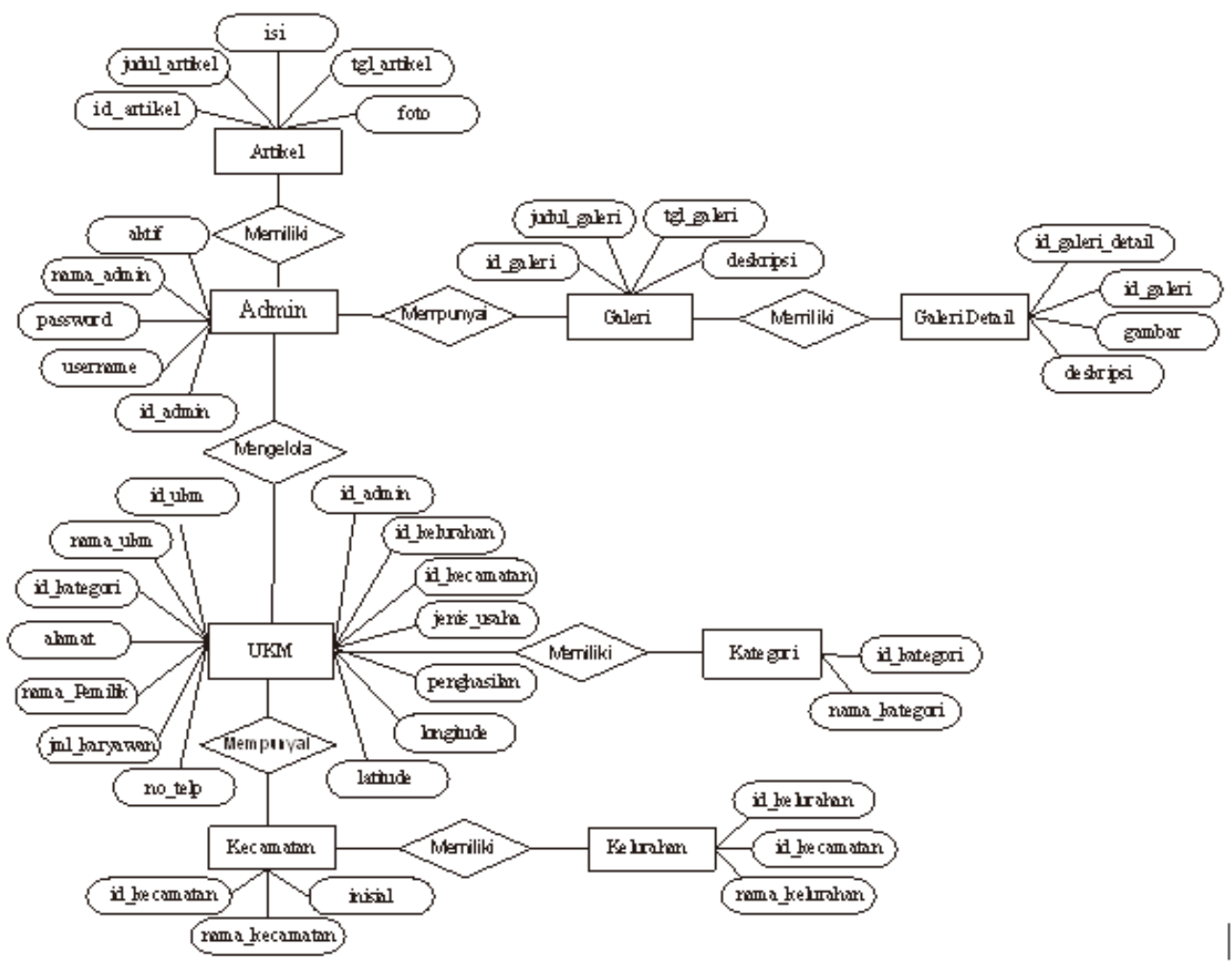

Gambar 2. ERD (Entity Relationship Diagram) 
IJSE - Indonesian Journal on Software Engineering, Vol.6, No. 1, Juni 2020, 56-63 pISSN: 2461-0690 I elSSN: 2714-9935

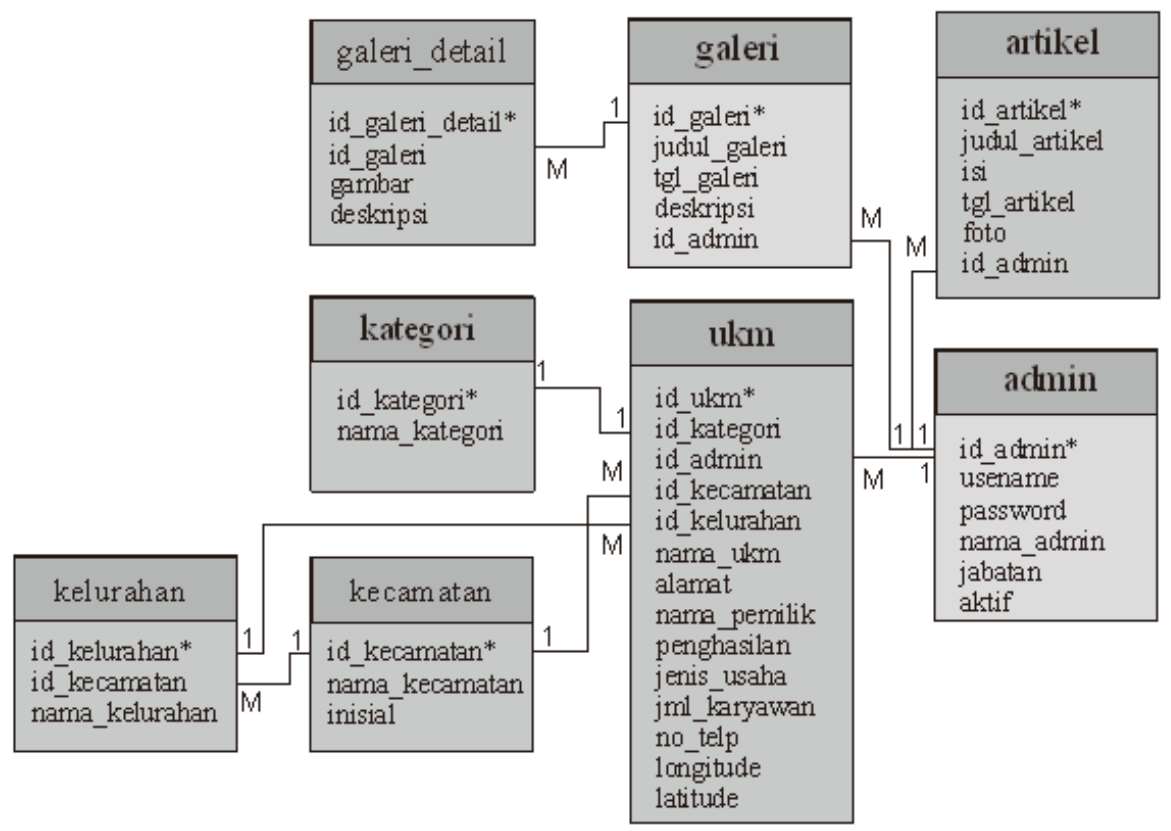

Gambar 3. LRS (Logical Record Structure)

3. Pengkodean

Setelah dilakukan pembuatan kode program maka tampilan antar muka sebagai berikut:

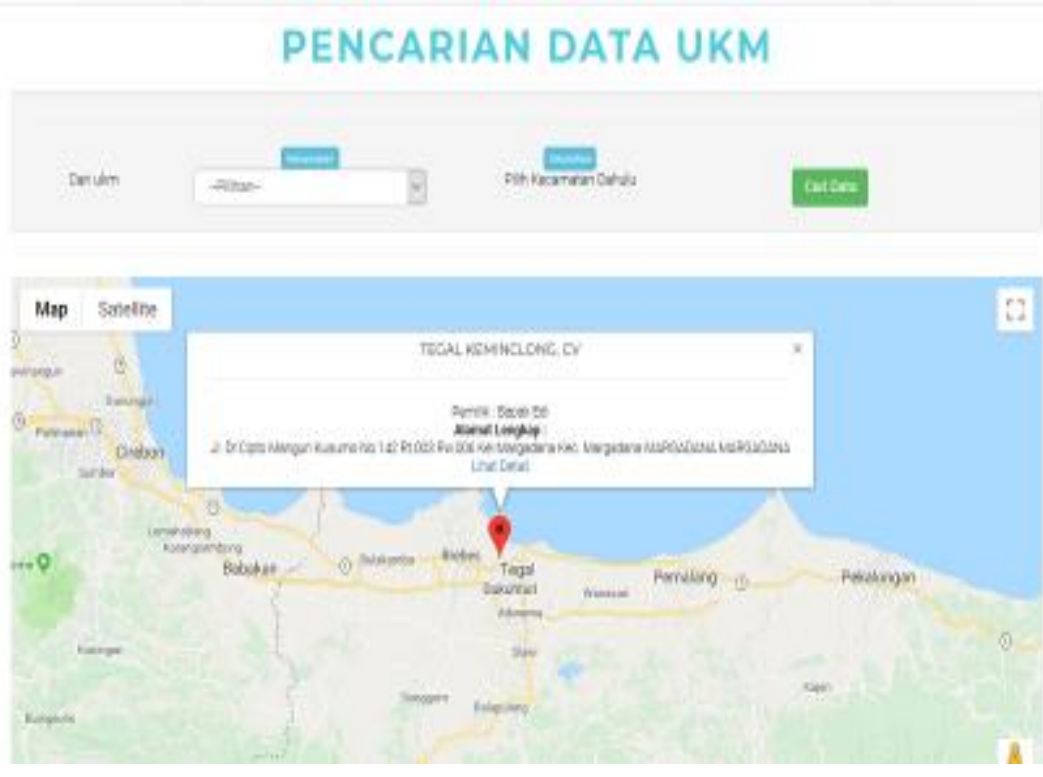

Gambar 4. Antar muka data lokasi UKM

Gambar 4, merupakan tampialn antar muka data UKM Letak Data UKM yang ada berdasarkan kecamatan serta kelurahan yang berada di Kota Tegal 


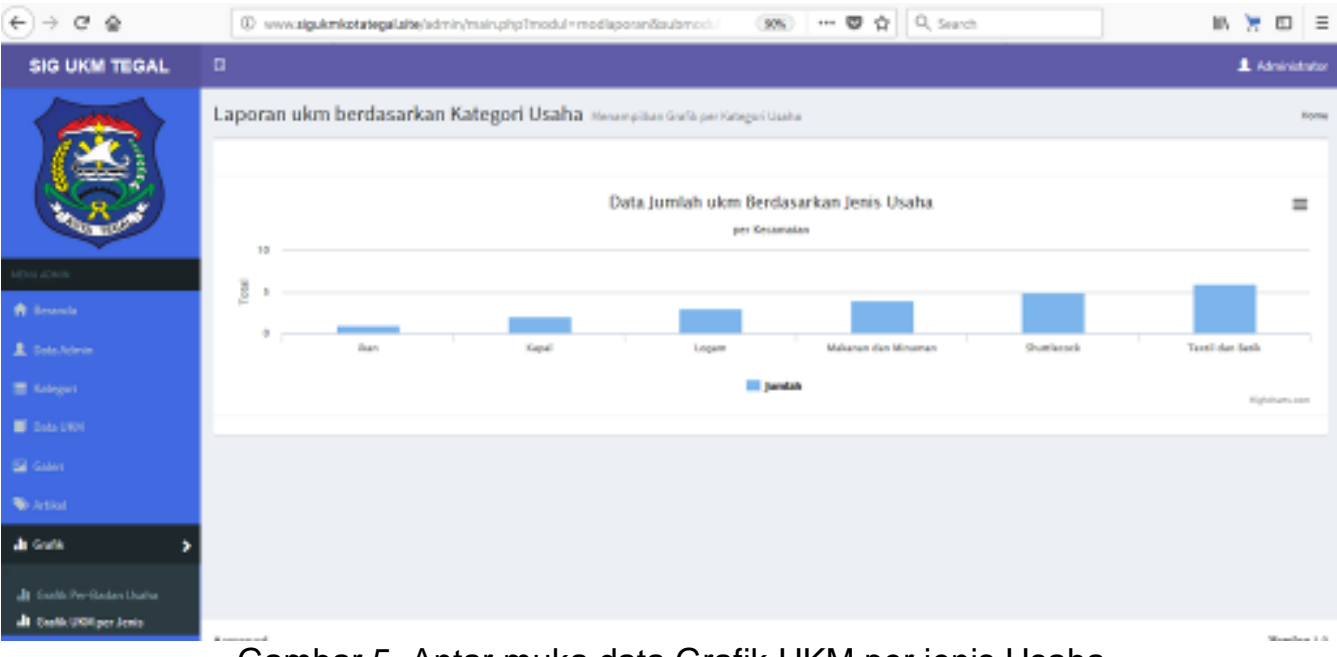

Gambar 5. Antar muka data Grafik UKM per jenis Usaha

Gambar 5, merupakan tampilan antar muka grafik UMKM Grafik UKM per jenis usaha yang ada di Kota Tegal berdasarkan kecamatan dan kelurahan berdasarkan badan usahanya.

Laporan Data ukm per Wilayah

\begin{tabular}{|c|c|c|c|c|c|c|c|}
\hline \multicolumn{2}{|c|}{ Kecamatan } & \multicolumn{6}{|l|}{ MARGADANA } \\
\hline Kelur & ahan & MARGADANA & & & & & \\
\hline No. & Nama ukm & Alamat & Kecamatan & Kelurahan & Pemilik & $\begin{array}{l}\text { Badan } \\
\text { Usaha }\end{array}$ & No. Telp \\
\hline 1 & TJAMAT PUTRA, CV & $\begin{array}{l}\text { Jalan Tanjan } 1152146 \text { Margadana - Krandon } 2 \text { Central } \\
\text { Java - Indonesia }\end{array}$ & MARGADANA & KRANDON & $\begin{array}{l}\text { Bapak } \\
\text { Wawan }\end{array}$ & $\mathrm{cV}$ & 0283353723 \\
\hline 3 & $\begin{array}{l}\text { TEGAL } \\
\text { KEMINCLONG, CV }\end{array}$ & $\begin{array}{l}\text { Jl. Dr.Cipto Mangun Kusumo No. } 142 \text { Rt.003 Rw.006 } \\
\text { Kel.Margadana Kec. Margadana }\end{array}$ & MARGADANA & MARGADANA & Bapak Edi & $\mathrm{cV}$ & 082223121963 \\
\hline 5 & $\begin{array}{l}\text { Olahan Ikan Asin Ibu } \\
\text { Wirih }\end{array}$ & Pesurungan Lor RT 06/03 & MARGADANA & $\begin{array}{l}\text { PESURUNGAN } \\
\text { LOR }\end{array}$ & Ibu Wirih & Tidak & \\
\hline
\end{tabular}

Gambar 6. Antar muka tampilan laporan

Gambar 6, merupakan tampilan antar muka laporan Halaman Laporan berfungsi untuk menampilkan Laporan yang ada pada sistem laporan tersebut dapat dicetak secara periodik perbulan, dan pertahun

\section{Pengujian}

Pengujian atau testing yang dilakukan menggunakan blackbox testing. Seluruh antar muka telah dilakukan testing. Berikut ini daitampilkan salah satu hasil pengujian.

Tabel 1. Blacbox Testing Form Login

\begin{tabular}{|l|l|l|l|c|c|}
\hline No & \multicolumn{1}{|c|}{ Skenario Pengujian } & \multicolumn{1}{|c|}{ Test Case } & \multicolumn{1}{c|}{ Hasil yang diharapkan } & $\begin{array}{c}\text { Hasil } \\
\text { Pengujian }\end{array}$ & \multicolumn{1}{c|}{ Kesimpulan } \\
\hline 1. & $\begin{array}{l}\text { Username dan Password } \\
\text { tidak diisi kemudian klik } \\
\text { tombol Login }\end{array}$ & $\begin{array}{l}\text { Username: Kosong } \\
\text { Password: } \\
\text { Kosong }\end{array}$ & $\begin{array}{l}\text { Sistem akan menolak akses dan } \\
\text { field akan diberi garis merah serta } \\
\text { menampilkan “Username dan } \\
\text { Password Kosong!." }\end{array}$ & $\begin{array}{c}\text { Sesuai } \\
\text { harapan }\end{array}$ & Valid \\
\hline 2. & $\begin{array}{l}\text { Username diisi dan } \\
\text { Password tidak diisi } \\
\text { kemudian klik tombol Masuk }\end{array}$ & $\begin{array}{l}\text { Username: Hilda } \\
\text { Password: } \\
\text { Kosong }\end{array}$ & $\begin{array}{l}\text { Sistem akan menolak akses dan } \\
\text { akan menampilkan pesan } \\
\text { "Masukan Password Terlebih } \\
\text { Dahulu" }\end{array}$ & $\begin{array}{c}\text { Sesuai } \\
\text { harapan }\end{array}$ & Valid \\
\hline .3. & $\begin{array}{l}\text { Username tidak diisi dan } \\
\text { Password diisi kemudian } \\
\text { klik tombol Masuk }\end{array}$ & $\begin{array}{l}\text { Username: Kosong } \\
\text { Password: } \\
\text { cicak }\end{array}$ & $\begin{array}{l}\text { Sistem akan menolak akses dan } \\
\text { field username akan diberi garis } \\
\text { merah serta menampilkan }\end{array}$ & $\begin{array}{c}\text { Sesuai } \\
\text { harapan }\end{array}$ & Valid \\
\hline
\end{tabular}




\begin{tabular}{|l|l|l|l|c|c|}
\hline & & & $\begin{array}{l}\text { "Masukan Username Terlebih } \\
\text { Dahulu" }\end{array}$ & \\
\hline 4. & $\begin{array}{l}\text { Username dan Password } \\
\text { diisi dengan data yang } \\
\text { salah kemudian klik tombol } \\
\text { Masuk }\end{array}$ & $\begin{array}{l}\text { Username: } \\
\text { fani } \\
\text { Password: fa05 }\end{array}$ & $\begin{array}{l}\text { Sistem akan menolak dan akan } \\
\text { menampilkan pesan "Login Gagal!, } \\
\text { Silahkan Periksa Kembali } \\
\text { Username dan Password Anda" }\end{array}$ & $\begin{array}{c}\text { Sesuai } \\
\text { harapan }\end{array}$ & Valid \\
\hline 5. & $\begin{array}{l}\text { Username dan Password } \\
\text { diisi dengan Ingkap dan } \\
\text { benar kemudian klik tombol } \\
\text { Masuk }\end{array}$ & $\begin{array}{l}\text { Username: cicak } \\
\text { Password: } \\
\text { Cicak }\end{array}$ & $\begin{array}{l}\text { Sistem menerima akses login dan } \\
\text { masuk kehalaman beranda admin }\end{array}$ & $\begin{array}{c}\text { Sesuai } \\
\text { harapan }\end{array}$ & Valid \\
\hline
\end{tabular}

\section{F. KESIMPULAN}

Sistem informasi geografis UKM Kota Tegal ini diharapkan dapat mempermudah Kepala Dinas Koperasi, UKM dan Perdagangan Kota Tegal dalam membuat sebuah keputusan dengan adanya laporan data UKM per-wilayah di Kota Tegal, dan juga terdapat informasi grafik UKM berdasarkan jenis usaha serta grafik jumlah UKM berdasarkan kelurahan. Selain itu bagi masyarakat sebagai dapat dengan mudah mencari data UKM melalui dan mengetahui letak lokasi UKM karen adidukung dengan tampilan peta sebaran UKM Kota Tegal. Harapan kedepan agar UKM Kota Tegal

\section{REFERENSI}

Abdullah BA. 2018. Sistem Informasi Geografis Sebaran UMKM Di Kota Cimahi. In: Seminar Nasional Teknologi Informasi dan Multimedia., p 1.7-7-1.7-12.

Eldita BuR, Kurniawan D, Febriansyah FE. 2018. Aplikasi Sistem Informasi Geografis Objek Wisata Berbasis Mobile Android Pada Dinas Kepemudaan, Olahraga Dan Pariwisata (Bidang Pariwisata) Kota Metro. J. Komputasi 6: 54-63.

Fridayantie EW, Mahdiati T. 2016. Rancang Bangun Sistem Informasi Permintaan ATK Berbasis Intranet (Studi Kasus Kejaksaan Negeri Rangkasbitung). J. Khatulistiwa Inform. IV: $126-138$.

Maita, Nurhikmah. 2018. Aplikasi pemetaan penyebaran industri kecil dan menengah di pekanbaru berbasis android 1,2. J. IIm. Rekayasa dan Manaj. Sist. Inf. 4: 60-66.

Minarni, Delfia. 2016. Sistem Informasi Geografis Usaha Mikro Kecil Dan Menengah ( Umkm ) Di Kota Padang Berbasis Web. J. Momentum 18: 1-10.

Rekatama FA. 2018. Pengembangan Sistem Informasi Pemetaan Sebaran UMKM Berbasis SIG Dalam Platform WEb Dengan Menerapkan Framework Laravel.

Rosa, Shalahuddin. 2016. Rekayasa Perangkat Lunak Terstruktur dan Berorientasi Objek. Bandung: Informatika Bandung.

Sasongko A. 2016. Sistem Informasi Geografis Berbasis Web Untuk Pemetaan Jalan dan Bangunan (Studi Kasus: Bidang Tata Ruang Dinas Pekerjaan Umum Kabupaten Kubu Raya). J. Khatulistiwa Inform. 4: 1-12.

UU No. 20 Tahun 2008. 2008. In: Usaha Mikro, Kecil, Menengah., p 1-31.

Warjiyono. 2017. Kajian E-Business Berbasis Cloud Computing Dalam Menghadapi Pasar Bebas Asean Economic Community 2015. Indones. J. Netw. Secur. 6: 24-31. 